\title{
Drug-Induced Bullous Sweet Syndrome with Multiple Autoimmune Features
}

\author{
Jared J. Lund, ${ }^{1}$ Erik J. Stratman, ${ }^{1}$ Deepa Jose, ${ }^{2}$ Ling Xia, ${ }^{3}$ Deborah Wilson, ${ }^{4}$ \\ and Mohammed Moizuddin ${ }^{2}$
}

${ }^{1}$ Department of Dermatology, Marshfield Clinic, 1000 N. Oak Avenue, Marshfield, 54449, USA

${ }^{2}$ Department of Internal Medicine, Marshfield Clinic, 1000 N. Oak Avenue, Marshfield, 54449, USA

${ }^{3}$ Department of Pathology, Marshfield Clinic, 1000 N. Oak Avenue, Marshfield, 54449, USA

${ }^{4}$ Department of Rheumatology, Marshfield Clinic, 1000 N. Oak Avenue, Marshfield, 54449, USA

Correspondence should be addressed to Erik J. Stratman, stratman.erik@marshfieldclinic.org

Received 12 March 2010; Revised 25 June 2010; Accepted 1 August 2010

Academic Editor: Thomas Dörner

Copyright (๑) 2010 Jared J. Lund et al. This is an open access article distributed under the Creative Commons Attribution License, which permits unrestricted use, distribution, and reproduction in any medium, provided the original work is properly cited.

Sweet syndrome (SS) (Acute Febrile Neutrophilic Dermatosis) has been reported in association with autoimmune phenomena including relapsing polychondritis, drug-induced lupus, and the development of antineutrophil cytoplasmic antibodies (ANCAs). However, a combination of these autoimmune features has not been reported. Herein, we report a case of drug-induced bullous SS with ocular and mucosal involvement, glomerulonephritis, and multiple autoimmune features including clinical polychondritis with antitype II collagen antibodies, ANCAs, antinuclear (HEp-2), and antihistone antibodies in a patient on hydralazine and carbamazepine.

\section{Introduction}

Sweet Syndrome (Acute Febrile Neutrophilic Dermatosis) is characterized by rapid onset of fever, leukocytosis, and painful erythematous edematous papules, plaques, and nodules. Etiologies include infections, particularly from upper respiratory or gastrointestinal sources; inflammatory and autoimmune diseases; pregnancy; malignancy; drug; and idiopathic. Rare clinical manifestations include bullous lesions, oral involvement, glomerulonephritis, myositis, and ocular manifestations including conjunctivitis, episcleritis, and iridocyclitis [1-3]. Sweet syndrome (SS) has been associated with autoimmune phenomena including relapsing polychondritis, drug-induced lupus, and development of antineutrophil cytoplasmic antibodies (ANCAs). However, a combination of all these features has not been reported. Herein, we report such a patient.

\section{Case Report}

An 86-year-old female with bipolar disorder was admitted with anxiety, insomnia, fatigue, and acute renal failure.
Although lithium levels were normal, lithium had been discontinued and replaced with carbamazepine $100 \mathrm{mg}$ daily 2 days prior to admission. She was also taking hydralazine $100 \mathrm{mg}$ three times daily for hypertension for 2 years with no dosage change in 8 months. On hospital day 8 , she developed fever and conjunctivitis followed by oral erosions and painful lesions on her nose, ears, back, and fingers.

On examination, she appeared acutely ill and was febrile $\left(38.4^{\circ} \mathrm{C}\right)$. Bilateral conjunctivitis with exudative discharge and periorbital edema was noted. Tense vesicles and bullae with surrounding erythema were noted on her scalp, nose, and back. The skin overlying the cartilaginous portions of both ears was erythematous and edematous with focal bullous change. The noncartilaginous lobes appeared normal. Erosions were noted on the hard palate and gingival mucosa (Figure 1). Tender hemorrhagic bullae were prominent on distal and lateral fingers (Figure 2).

Laboratory testing revealed elevated C-reactive protein at $14 \mathrm{mg} / \mathrm{dl}$ (normal $=0$ to $1 \mathrm{mg} / \mathrm{dL})$ and erythrocyte sedimentation rate of $72 \mathrm{~mm} /$ hour (normal $=0$ to $17 \mathrm{~mm} /$ hour). Her white blood cell count was normal at $5.5 / \mathrm{mm}^{3}$ (normal $=4.1$ to $10.9 / \mathrm{mm}^{3}$ ) and hemoglobin was low at $9.7 \mathrm{gm} / \mathrm{dL}$ 


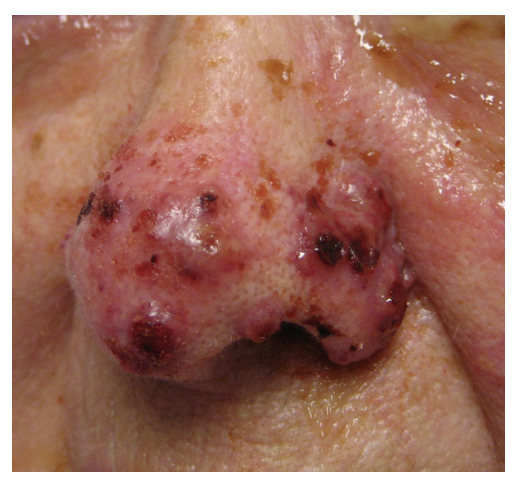

(a)

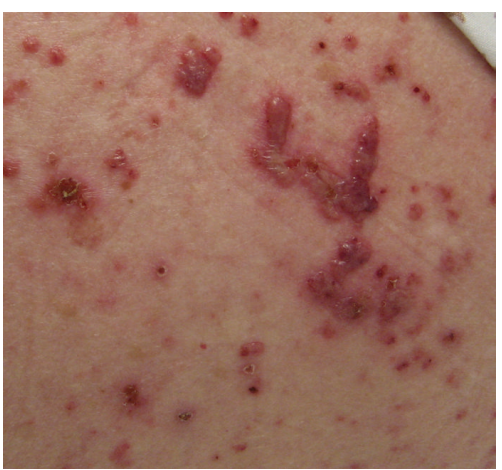

(b)

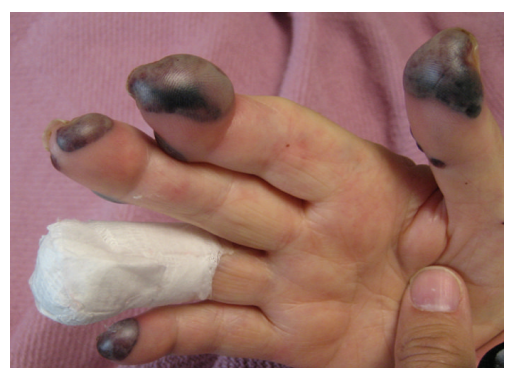

(c)

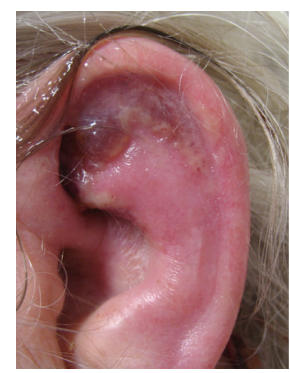

(d)

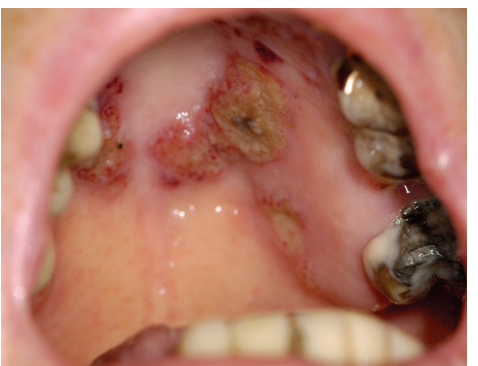

(e)

Figure 1: (a) Drug-induced Sweet Syndrome demonstrating tense vesicles and bullae with surrounding erythema over nose. (b) Tense inflammatory vesicles and bullae over central back. (c) Hemorrhagic bullae of distal finger pads and lateral fingers. (d) Erythema, edema, and focal bullous change overlying the cartilaginous portions of both ears. The non-cartilagenous lobes demonstrated no inflammatory changes. (e) Bullous lesions and erosions on the hard palate.

TABLE 1: Drugs associated with Sweet's Syndrome.

\begin{tabular}{l}
\hline Abacavir \\
All-trans retinoic acid \\
Bortezomib \\
Carbamazapine \\
Celecoxib \\
Clozapine \\
Diclofenac \\
Diazepam \\
Furosemide \\
Granulocyte colony-stimulating factor \\
Hydralazine \\
Imatinib \\
Lenalidomide \\
Minocycline \\
Nitrofurantoin \\
Norfloxacin \\
Ofloxacin \\
Oral Contraceptives \\
Pegfilgastrin \\
Propylthiouracil \\
Quinupristin/Dalfopristin \\
Trimethoprim-sulfamethoxazole \\
\hline
\end{tabular}

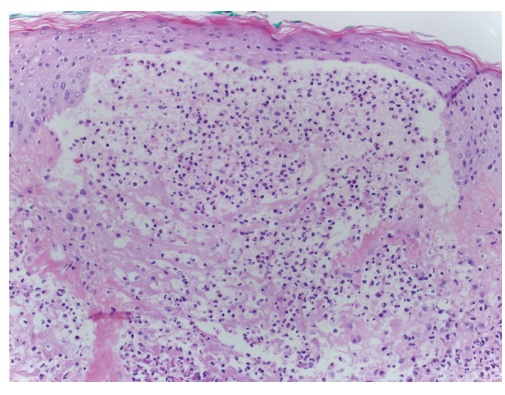

FIgURE 2: $3 \mathrm{~mm}$ punch biopsy-upper back skin with focal subepidermal vesicles with neutrophilic microabscesses, perivascular and interstitial neutrophilic dermal infiltrate with leukocytoclasis 10x.

(normal $=11.7$ to $15.5 \mathrm{gm} / \mathrm{dL})$. Serum creatinine was $2.1 \mathrm{mg} / \mathrm{dl}$ (normal $=11.7$ to $15.5 \mathrm{gm} / \mathrm{dL}$ ). Serum creatinine was $2.1 \mathrm{mg} / \mathrm{d}$ and urinalysis demonstrated a new proteinuria $(30 \mathrm{mg} / \mathrm{dl})$ with hematuria (51 to $100 \mathrm{red}$ blood cells/hp). Further labs showed positive AntiNuclear Antibody (HEp-2) with homogenous pattern of $1: 640$ (normal < $1: 160$ ). Antihistone antibodies were elevated at 3.7 units (positive $>1.5$ units, Mayo Medical Laboratories). Perinuclear antineutrophil cytoplasmic antibodies (pANCAs) were positive to myeloperoxidase and proteinase 3 at 200 units/ml (normal $=0$ to 9 units $/ \mathrm{ml}$ ) and 48.5 units $/ \mathrm{ml}$ (normal $=0$ to 


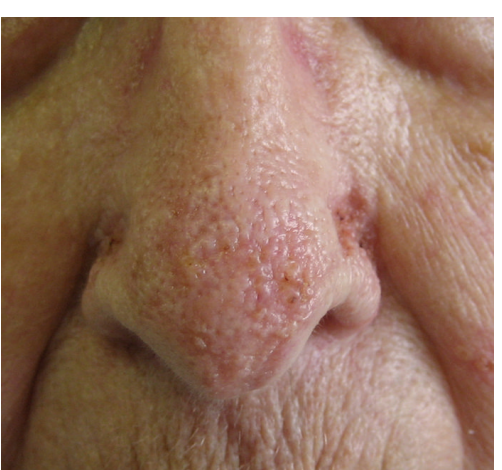

(a)

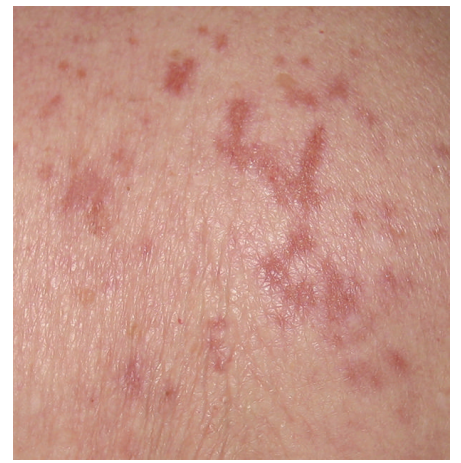

(b)

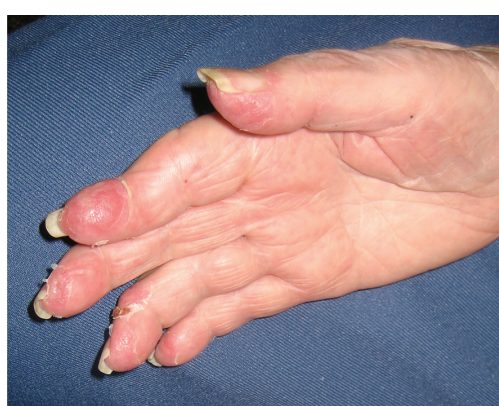

(c)

FIGURE 3: Clearing of affected areas 3 weeks following discharge on tapering dose of prednisone.

3.5 units $/ \mathrm{ml}$ ), respectively. Anti-double-stranded DNA, antiSmith, anti-RNP, SSA, SSB, SCL-70, or JO-1 antibodies were not detected, and complement levels were normal. Blood and urine cultures were negative. Serum protein electrophoresis showed acute phase reaction pattern.

Three-millimeter punch biopsies from the back and finger demonstrated focal subepidermal vesicles with neutrophilic microabscesses, perivascular and interstitial neutrophilic dermal infiltrate, and leukocytoclasis without vasculitis (Figure 2). Perilesional direct immunoflourescence (DIF) was negative. The patient declined ear cartilage biopsy, but anti-type II collagen antibodies were positive (47.6 EU/ml; normal <20 EU/ml; Mayo Medical Laboratories).

Drug-induced SS was suspected. Both carbamazepine and hydralazine were discontinued, and the patient was started on oral prednisone $60 \mathrm{mg}$ daily. The patient declined renal biopsy. Her renal function, skin lesions, and mucosal lesions improved on prednisone, and she was discharged on a tapering dose. Skin lesions were resolved three weeks following discharge (Figure 3) Her MPO and PR-3 titers (57.7 units/ml and 11.1 units $/ \mathrm{ml}$, respectively) also decreased as her symptoms improved. The patient died of unknown causes 2 months following discharge, still on a tapering prednisone dose.

\section{Discussion}

The criteria for drug-induced Sweet Syndrome (SS) include the following [4]: an abrupt onset of painful erythematous plaques or nodules; histopathologic evidence of a dense neutrophilic infiltrate without evidence of leukocytoclastic vasculitis; pyrexia $>38^{\circ} \mathrm{C}$; temporal relationship between drug ingestion and clinical presentation, or recurrence after drug rechallenge; temporal relationship of resolution of lesions after drug withdrawal or treatment with systemic corticosteroids. In a review of 49 cases of drug-induced SS, leukocytosis was only documented in 11 cases [5]. Therefore, a normal white blood cell count should not rule out this diagnosis. Drug-induced SS occurs more often in women. The average time to onset of clinical symptoms after beginning drug therapy is 7.5 days $[4,5]$.

The pathophysiology of drug-induced SS is not clearly understood, and additional associated autoimmune features have been reported. Carbamazepine is known to cause druginduced SS and drug-induced systemic lupus erythematosus (SLE) [6-8]. While carbamazepine is the most likely trigger, as onset of this therapy occurred 10 days prior to the development of our patient's cutaneous disease and fever, hydralazine was also considered, since hydralazine-induced SLE may occur 6 months to 6 years after starting the drug [912]. Since both drugs reportedly induce drug-induced SLE, a bullous variant of this disease must be considered in our patient.

In reports of drug-induced bullous SLE, histopathologic examination demonstrated an interstitial neutrophilic infiltrate with subepidermal blister formation, interface change, and a positive DIF showing linear deposition of IgA and $\operatorname{IgG}$ at the basement membrane zone $[13,14]$. Our patient had antihistone antibodies which may occur in drug-induced SLE [7], but the biopsy and clinical features best supports SS. Fever, oral erosions, and glomerulonephritis have all been reported in SS, but renal manifestations rarely occur in druginduced SLE [8]. In this case, it is difficult to conclude that the patient's glomerulonephritis was directly related, as she was admitted with renal failure. Medications may induce SS with autoantibody profiles that mimic drug-induced SLE, but the skin eruptions lack characteristic histologic features of cutaneous lupus [12].

Sweet Syndrome has also been associated with relapsing polychondritis [15-22], usually in association with an underlying hematologic malignancy, dyscrasia, or solid malignancy. Our patient's clinical presentation of auricular inflammation that spared the non-cartilaginous lobes with anti-type II collagen antibodies supports the diagnosis of drug-induced autoimmune polychondritis.

Cytoplasmic ANCA (c-ANCA) can occur in patients with SS [23]. Multiple cases of drug-induced SS in association with positive p-ANCA antibodies have also been reported $[24,25]$. The presence of $\mathrm{p}-\mathrm{ANCA}$ with anti-MPO antibodies 
appears to occur more commonly in drug-induced cases of SS [26]. ANCA may contribute to the pathogenesis of neutrophilic dermatoses [25].

\section{Conclusion}

Drug-induced SS is a unique dermatosis which may have unusual clinical and laboratory associations. Either carbamazepine or hydralazine may have incited this severe reaction. This case demonstrates unusual clinical features and multiple associated drug-induced autoimmune phenomena.

\section{Conflict of Interests}

No sources of funding were used to assist in the preparation of this case report. The authors have no conflict of interests that are directly relevant to the content of this case report.

\section{References}

[1] B. K. Draper, J. R. Robbins, and G. P. Stricklin, "Bullous Sweet's syndrome in congenital neutropenia: association with pegfilgrastim," Journal of the American Academy of Dermatology, vol. 52, no. 5, pp. 901-905, 2005.

[2] S. Voelter-Mahlknecht, J. Bauer, G. Metzler, G. Fierlbeck, and G. Rassner, "Bullous variant of Sweet's syndrome," International Journal of Dermatology, vol. 44, no. 11, pp. 946947, 2005.

[3] C. Y. Neoh, A. W. H. Tan, and S. K. Ng, "Sweet's syndrome: a spectrum of unusual clinical presentations and associations," British Journal of Dermatology, vol. 6, no. 3, pp. 480-485, 2007.

[4] D. C. Walker and P. R. Cohen, "Trimethoprimsulfamethoxazole-associated acute febrile neutrophilic dermatosis: case report and review of drug-induced Sweet's syndrome," Journal of the American Academy of Dermatology, vol. 34, no. 5, pp. 918-923, 1996.

[5] M. Sáez, M. García-Bustínduy, A. Noda et al., "Drug-induced Sweet's syndrome," Journal of the European Academy of Dermatology and Venereology, vol. 18, no. 2, p. 233, 2004.

[6] D. Sitjas, L. Puig, M. Cuatrecasas, and J. M. De Moragas, "Acute febrile neutrophilic dermatosis (Sweet's syndrome)," International Journal of Dermatology, vol. 32, no. 4, pp. 261268, 1993.

[7] L. Pelizza, P. De Luca, M. L. La Pesa, and A. Minervino, "Drug-induced systemic lupus erythematosus after 7 years of treatment with carbamazepine," Acta Biomedica de l'Ateneo Parmense, vol. 77, no. 1, pp. 17-61, 2006.

[8] S. P. Verma, N. Yunis, A. Lekos, and R. S. Crausman, "Carbamazepine-induced systemic lupus erythematosus presenting as cardiac tamponade," Chest, vol. 117, no. 2, pp. 597598,2000 .

[9] E. Gilmour, R. J. G. Chalmers, and D. J. Rowlands, "Druginduced Sweet's syndrome (acute febrile neutrophilic dermatosis) associated with hydralazine," British Journal of Dermatology, vol. 133, no. 3, pp. 490-491, 1995.

[10] W. Sequeira, R. B. Polisky, and D. P. Alrenga, "Neutrophilic dermatosis (Sweet's syndrome). Association with a hydralazine-induced lupus syndrome," American Journal of Medicine, vol. 81, no. 3, pp. 558-560, 1986.

[11] O. Servitje, M. Ribera, X. Juanola, and J. Rodriguez-Moreno, "Acute neutrophilic dermatosis associated with hydralazineinduced lupus," Archives of Dermatology, vol. 123, no. 11, pp. 1435-1436, 1987.
[12] R. Ramsey-Goldman, T. Franz, F. X. Solano, and T. A. Medsger Jr., "Hydralazine induced lupus and Sweet's syndrome report and review of the literature," Journal of Rheumatology, vol. 17, no. 5, pp. 682-684, 1990.

[13] H.-Y. Thong, C.-Y. Chu, and H.-C. Chiu, "Methimazoleinduced antineutrophil cytoplasmic antibody (ANCA)associated vasculitis and lupus-like syndrome with a cutaneous feature of vesiculo-bullous systemic lupus erythematosus," Acta Dermato-Venereologica, vol. 82, no. 3, pp. 206-208, 2002.

[14] C. Condon, M. Phelan, and J. F. Lyons, "Penicillamineinduced type II bullous systemic lupus erythematosus," British Journal of Dermatology, vol. 136, no. 3, pp. 474-475, 1997.

[15] N. Fujimoto, S. Tajima, A. Ishibashi, A. Ura-Ishikou, and I. Manaka, "Acute febrile neutrophilic dermatosis (Sweet's syndrome) in a patient with relapsing polychondritis," British Journal of Dermatology, vol. 139, no. 5, pp. 930-931, 1998.

[16] C. Francès, R. El Rassi, J. L. Laporte, M. Rybojad, T. Papo, and J.-C. Piette, "Dermatologic manifestations of relapsing polychondritis: a study of 200 cases at a single center," Medicine, vol. 80, no. 3, pp. 173-179, 2001.

[17] D. L. Fett, L. E. Gibson, and W. P. D. Su, "Sweet's syndrome: systemic signs and symptoms and associated disorders," Mayo Clinic Proceedings, vol. 70, no. 3, pp. 234-240, 1995.

[18] L. Astudillo, F. Launay, L. Lamant et al., "Sweet's syndrome revealing relapsing polychondritis," International Journal of Dermatology, vol. 43, no. 10, pp. 720-722, 2004.

[19] P. R. Cohen, "Sweet's syndrome and relapsing polychondritis: is their appearance in the same patient a coincidental occurrence or a bona fide association of these conditions?" International Journal of Dermatology, vol. 43, no. 10, pp. 772777, 2004.

[20] C. Vestergaard, H. Soelvsten, M. Ramsing, E. S. Hansen, and M. Deleuran, "Concomitant Sweet's syndrome and relapsing polychondritis," Acta Dermato-Venereologica, vol. 87, no. 5, pp. 426-427, 2007.

[21] T. Kawakami, A. Kawase, S. Takeuchi et al., "Sweet syndrome subsequent to relapsing polychondritis and myelodysplastic syndrome in a Japanese patient," Acta Dermato-Venereologica, vol. 88, no. 5, pp. 517-519, 2008.

[22] H. Wastiaux, B. Hervier, C. Durant et al., "Sweet's syndrome as the presenting manifestation of relapsing polychondritis," Revue de Medecine Interne, vol. 31, no. 5, pp. e1-e3, 2010.

[23] D. Kemmett, D. J. Harrison, and J. A. A. Hunter, "Antibodies to neutrophil cytoplasmic antigens: a serologic marker for Sweet's syndrome," Journal of the American Academy of Dermatology, vol. 24, no. 6 I, pp. 967-969, 1991.

[24] R. M. Miller, T. A. Darben, J. Nedwich, and J. Savige, "Propylthiouracil-induced antineutrophil cytoplasmic antibodies in a patient with Graves' disease and a neutrophilic dermatosis," British Journal of Dermatology, vol. 141, no. 5, pp. 943-944, 1999.

[25] H. K. Choi, P. A. Merkel, A. M. Walker, and J. L. Niles, "Drug-associated antineutrophil cytoplasmic antibodypositive vasculitis: prevalence among patients with high titers of antimyeloperoxidase antibodies," Arthritis and Rheumatism, vol. 43, no. 2, pp. 405-413, 2000.

[26] S. Darné, S. Natarajan, and C. Blasdale, "Do antineutrophil cytoplasmic antibodies (ANCA) play a key role in neutrophilic dermatoses? A case of propylthiouracil-induced neutrophilic dermatosis with positive perinuclear ANCA," Clinical and Experimental Dermatology, vol. 35, no. 4, pp. 406-408, 2010. 


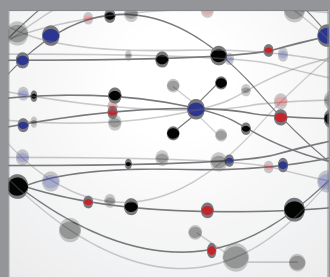

The Scientific World Journal
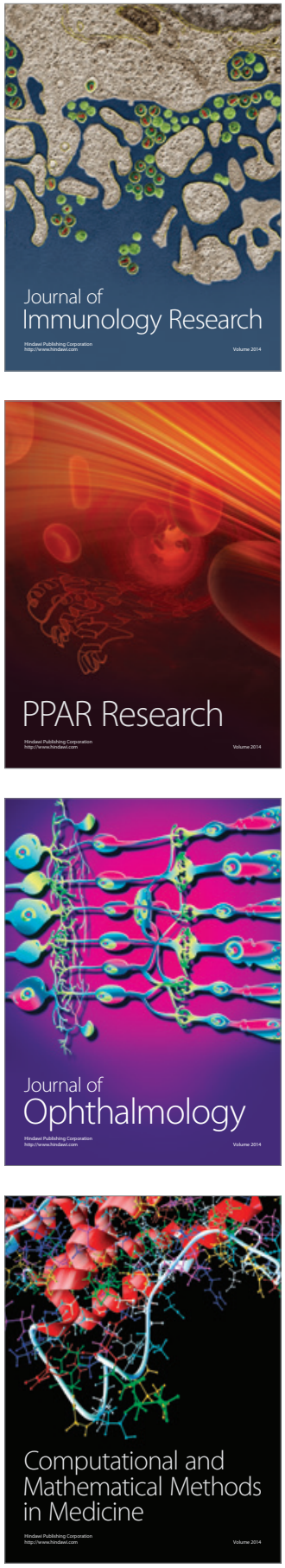

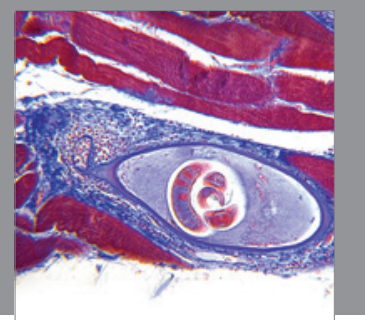

Gastroenterology

Research and Practice
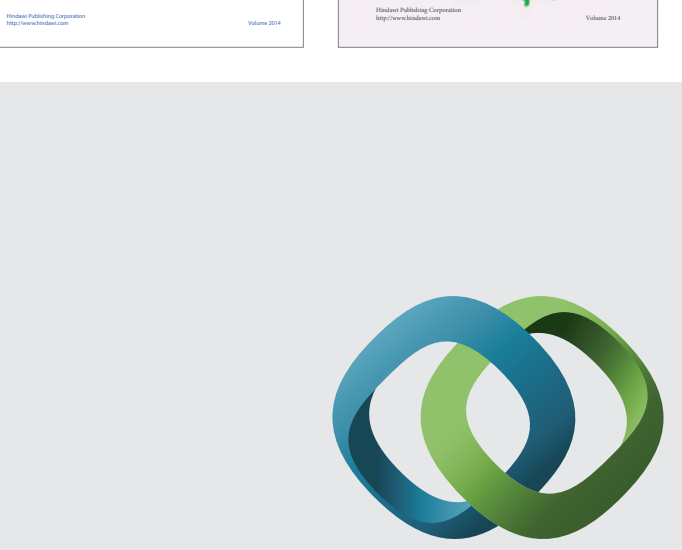

\section{Hindawi}

Submit your manuscripts at

http://www.hindawi.com
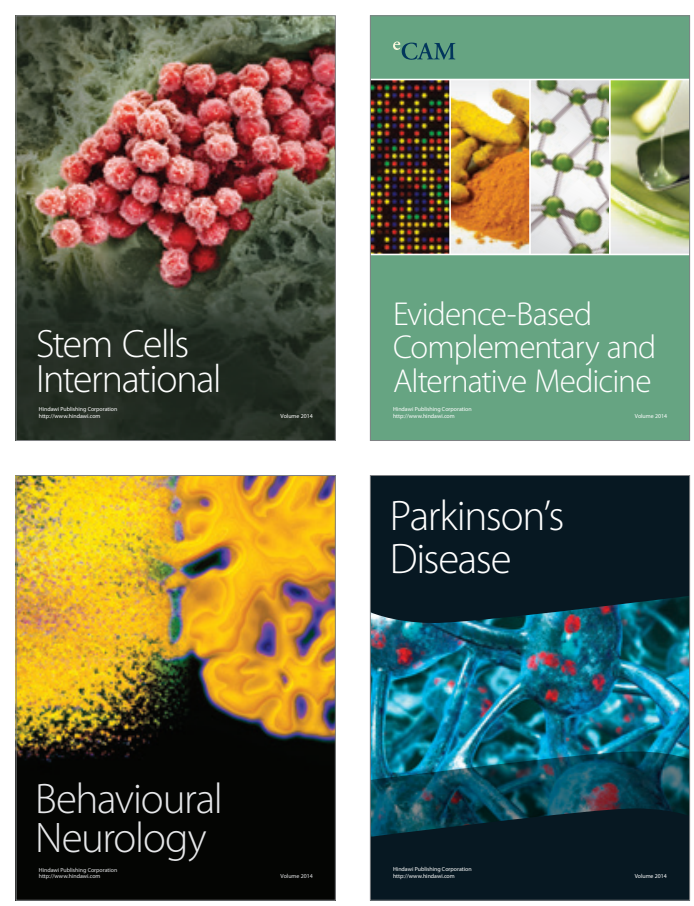

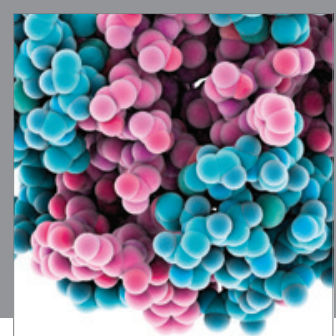

Journal of
Diabetes Research

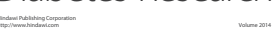

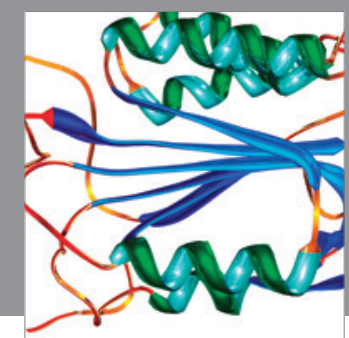

Disease Markers
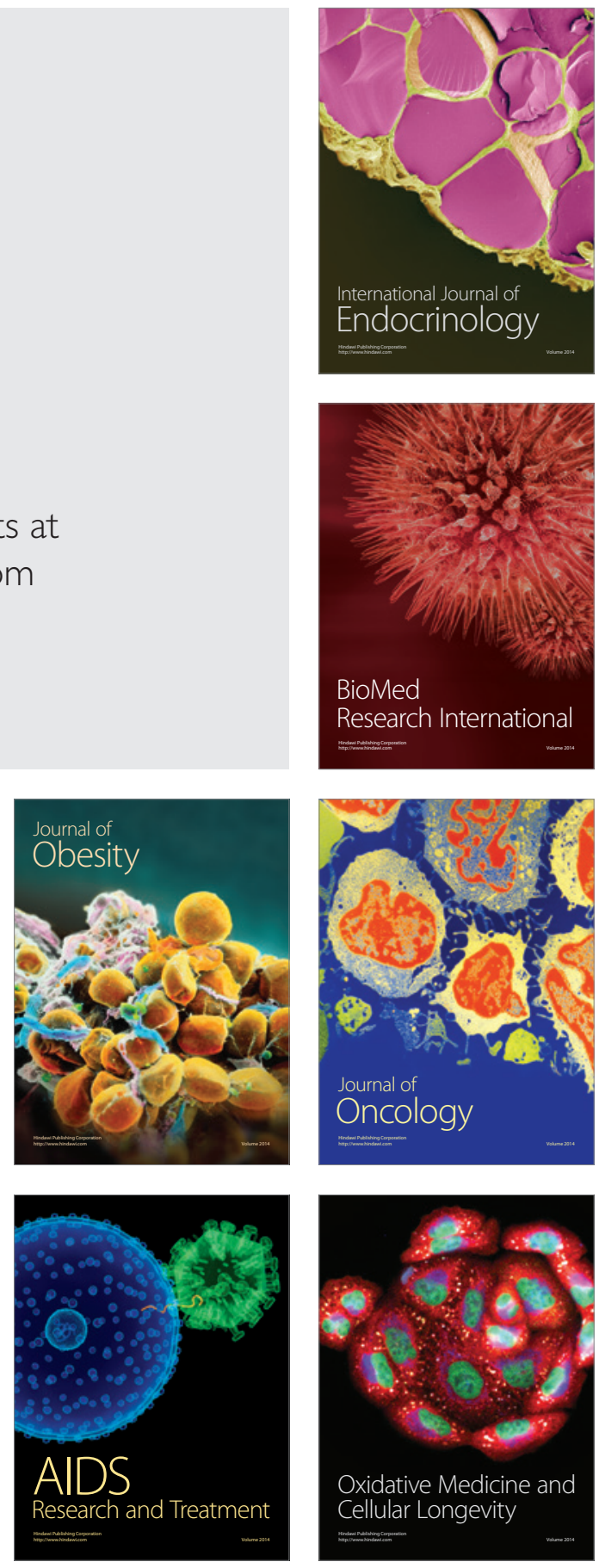